\title{
Cardiac Magnetic Resonance in the Assessment of Chagas Disease and its Complications
}

\author{
Ariane Binoti Pacheco ${ }^{1,2}{ }^{\circledR}$, Rodrigo de Jesus Louzeiro Melo ${ }^{(1)}$, Carlos Eduardo Rochitte ${ }^{2(0)}$ \\ Multiscan Inteligência Diagnóstica', Vitória, ES - Brazil \\ Universidade de São Paulo², São Paulo, SP-Brazil
}

\begin{abstract}
The well-known occurrence of Chagas disease in endemic areas has become a worldwide problem, and cardiac magnetic resonance allows the early detection of cardiac involvement and complications of this disease. Cardiac magnetic resonance is a useful tool in all phases of Chagas disease, and new promising techniques using T1 mapping and extracellular volume measurements are able to detect cardiac involvement even earlier than conventional techniques.
\end{abstract}

\section{Introduction}

The protozoan Trypanosoma cruzi is the causal agent of Chagas disease (CD), considered a significant global health problem. It affects the young productive population and is responsible for losses of around 752 000 working days in endemic countries. ${ }^{1}$ The migratory flux between endemic and non-endemic countries has spread CD worldwide and turned it into a global health problem, especially in countries with little knowledge on $\mathrm{CD}$ and its transmission. ${ }^{2-4}$

The natural progression of $\mathrm{CD}$ is divided in acute and chronic phases. The chronic phase is subdivided into indeterminate and determinate forms. The pathogenesis of $\mathrm{CD}$ involves an inflammatory response, as well as cellular damage and fibrosis that can be identified by cardiac magnetic resonance (CMR) imaging sequences.

\section{Keywords}

Chagas Diseases/complications; Chagas Cardiomyopathy/ complications; Fibrosis; Heart Failure; Magnetic Resonance Imaging/methods; Gadolinium /radiation effects; Extracellular Volume; T1 Mapping; Endemic Diseases.
CMR has been applied to evaluate several cardiomyopathy etiologies; it is considered efficient in the diagnosis of the different stages of $\mathrm{CD}$ and for determining prognosis, in addition to being a noninvasive method that does not expose the patient to ionizing radiation ${ }^{5}$.

Different CMR sequences are available to confirm early or late cardiac involvement in patients with $C D$ and to investigate heart failure of unknown causes where typical findings of $\mathrm{CD}$ could provide additional diagnostic information.

\section{The diagnostic role of CMR in acute CD}

Most patients with acute $\mathrm{CD}$ are oligosymptomatic and hardly ever seen in non-endemic areas; it is estimated that only $1-2 \%$ of the cases are diagnosed. ${ }^{5}$ In this phase, mortality is high and some patients develop severe myocarditis, meningoencephalitis, or both. Accurate diagnosis in the acute phase is particularly important because of the high probability of cure reached through the use of antiparasitic drugs. ${ }^{6}$

The consequences of heart muscle inflammation resulting from cardiac cell injury caused by T. cruzi and its related immune reactions can be identified by CMR using T2-weighted and late gadolinium enhancement (LGE) sequences for detecting myocarditis.

The T2-weighed sequence is able to identify areas of signal hyperintensity corresponding to myocardial edema using inversion pulses to suppress blood contrast and fat signals. On the other hand, the LGE sequence reveals regions of myocardial necrosis/fibrosis due to myocardial injury. This sequence is performed $10-20 \mathrm{~min}$ after the injection of a gadolinium-based contrast agent that reaches the myocardium and is distributed within the extracellular space; areas containing dead heart muscle cells retain the gadolinium and generate white images (Figure 1).

Mailing Address: Carlos Eduardo Rochitte

Departamento de Imagem Cardiovascular, Universidade de São Paulo, Instituto do Coração do HCFMUSP

Av. Dr. Enéas Carvalho de Aguiar, 44. Postal Code: 05403-900, Cerqueira César, São Paulo, SP - Brazil. 


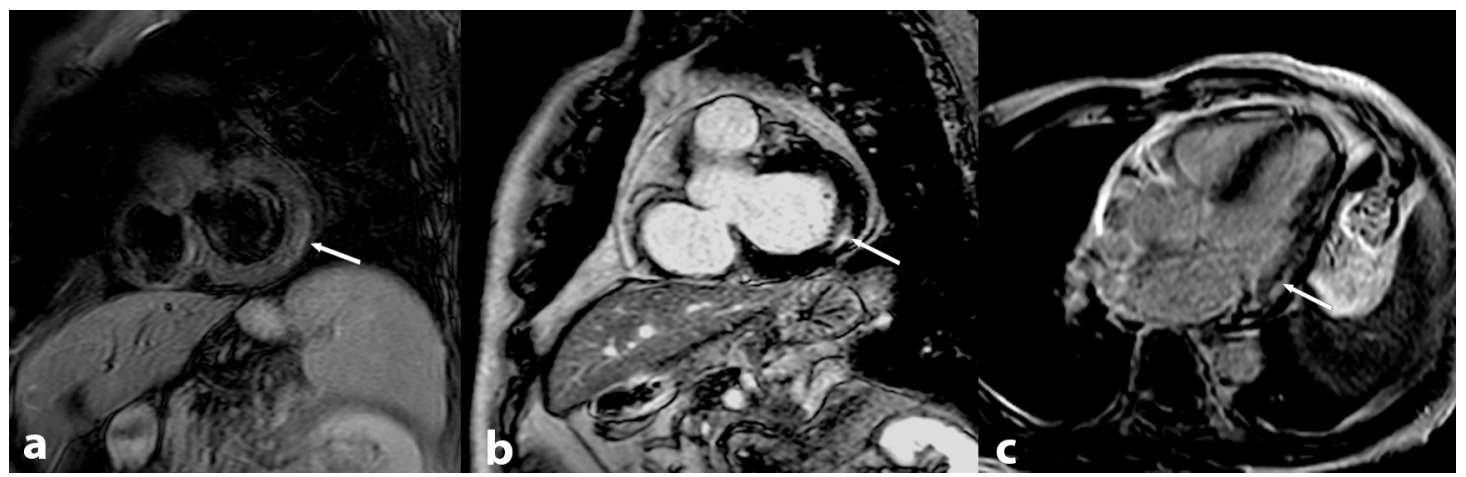

Figure 1 - Example of acute Chagas disease. In a, T2-weighted edema imaging demonstrating area of signal hyperintensity in the LV basal inferoseptal segment (short axis view) corresponding myocardial edema (arrow). In b and c, LGE imaging revels area of myocardial necrosis/fibrosis in the same region (arrow).

Fortunately, antiparasitic drugs cure $50-80 \%$ of patients with acute $\mathrm{CD}$ and are able to prevent progression to the chronic phase. ${ }^{7}$ However, since most patients are unaware of the disease and the diagnosis is hardly performed during the acute phase, it usually resolves spontaneously.

\section{The diagnostic role of CMR in chronic CD}

Approximately $30 \%$ of non-treated patients develop chronic CD after the acute phase. ${ }^{8}$ Most of them remain in the indeterminate form, with neither clinically apparent disease nor radiologic or electrocardiographically evident abnormalities for a long period or even a lifetime. In the chronic phase, CD can only be diagnosed by positive serology and/ or xenodiagnosis tests.

CMR allowed the observation of myocardial fibrosis (MF) and edema in some patients in the chronic phase of $\mathrm{CD}$; this contradicted the classical definition of this phase and revealed a less benign scenario than previously believed. ${ }^{9}$ Rochitte et al., ${ }^{10}$ used LGE in patients at various stages of CD and have demonstrated MF in $20 \%$ of patients in the indeterminate form..${ }^{10}$ Moreover, Torreão et al., ${ }^{11}$ revealed evidences of myocardial inflammation even long after the acute phase using T2-weighted and early gadolinium enhancement sequences, which corroborated histopathological findings in vivo. ${ }^{11,12}$

Approximately $30 \%$ to $40 \%$ of patients with CD will develop a determinate form of the disease 10-30 years after infection, with cardiac and/or digestive involvement; $5 \%$ to $10 \%$ will develop it directly after the acute phase 7
Chronic Chagas cardiomyopathy is the most important complication of $\mathrm{CD}$ and its pathogenesis is related to parasite-induced and immune-mediated myocardial injury, cardiac dysautonomia, and ischemia. ${ }^{13}$ It can present itself as heart failure, cardiac arrhythmia, and pulmonary or systemic thromboembolism.

The small and progressive damage secondary to chronic myocarditis and myocardial perfusion abnormalities results in regional cardiac dysfunction. Extensive regional damage leads to cardiac enlargement, myocardial dysfunction, and heart failure, which is responsible for mortality rates of around $50 \%$ in 4 years. Cardiac involvement is usually biventricular, with a more pronounced failure of the right ventricle (RV). ${ }^{14}$ Some patients may develop isolated RV dysfunction that can be detected early by CMR (Figure 2). ${ }^{1.5}$

The assessment of cardiac volumes and function can be performed using cine CMR. This technique presents advantages over echocardiography mainly in RV measurement, which can be performed directly by the Simpson method instead of being calculated by geometric approximation. ${ }^{16}$ Cine CMR provides an excellent myocardium-to-cavity contrast ratio, allowing the accurate delineation of endocardial borders; this is especially important in patients with significant changes in ventricular geometry such as ventricular apical aneurysm, a typical finding of chronic CD (Figure 3). Owing to these advantages, it is considered a gold standard technique for assessing volume and cardiac function. 


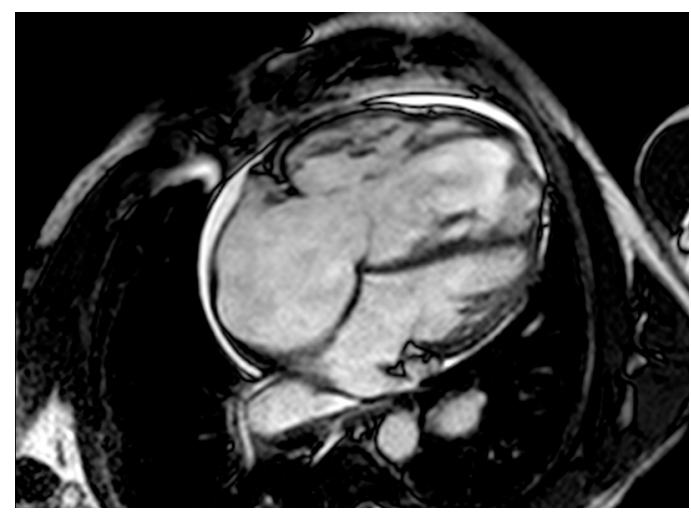

Figure 2 - A 50-year-old man present isolated RV involvement secondary to chronic Chagas disease easily detected by cine-CMR sequence.

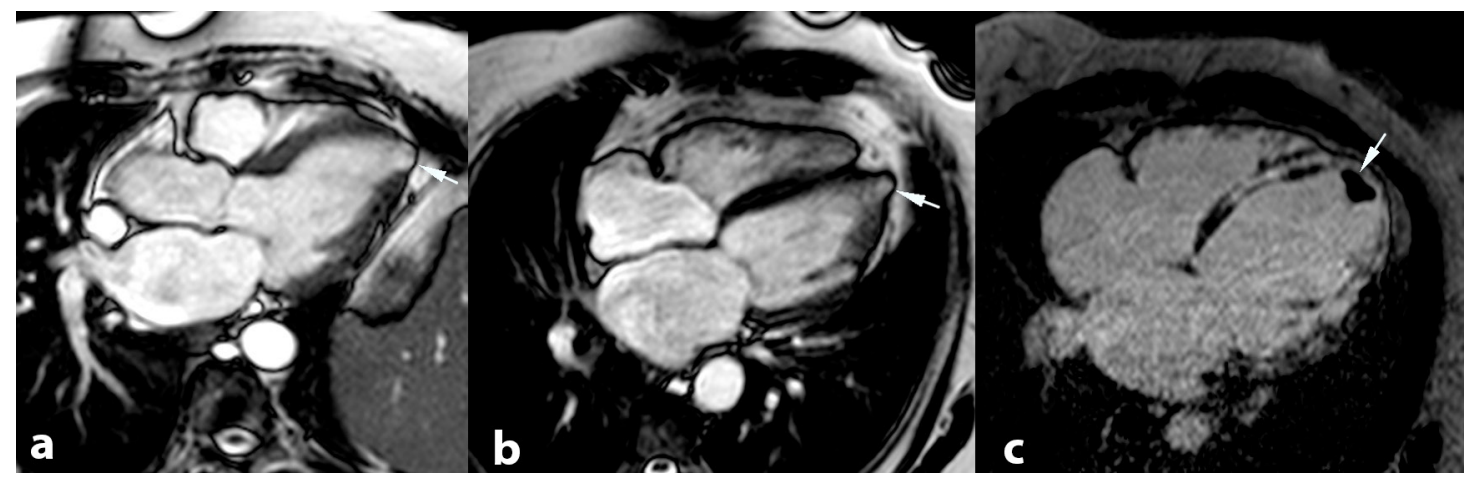

Figure 3 - Examples of complications of chronic Chagas disease in two representative patients. First patient: (a-b) cine-CMR reveals typical ventricular apical aneurysm (vorticilar) (arrows). Second patient: (c) LGE-CMR reveals apical thrombus (arrow) and LV myocardial fibrosis.

Adding myocardial tagging in cine CMR improves the detection of regional dysfunction through the visualization of myocardial deformation, which is an early abnormality of $\mathrm{CD}$. The assessment of myocardial deformation has recently advanced through speckletracking echocardiography and feature tracking by CMR. These techniques provide the assessment of ventricular dynamics, including the performance of quantitative segmental analyses of ventricular function, while global systolic function is still preserved ${ }^{17}$ Although the role of feature tracking by CMR in CD still needs to be assessed and standardized, speckle-tracking echocardiography has been extensively studied in patients with this disease.

Due to the very low sensitivity of echocardiography in detecting RV systolic dysfunction in patients with $C D$, speckle-tracking echocardiography has been used in the detection of RV impairment ${ }^{18}$, 19 and the early involvement of the left ventricle (LV) even in patients with preserved LV ejection fractions. ${ }^{20-22}$

An analysis performed in patients in early stages of $\mathrm{CD}$ observed, through CMR, a decrease in global longitudinal and circumferential LV strain only in patients with MF. ${ }^{23}$

The emergence of a perfusion CMR sequence allowed physicians to identify myocardial perfusion abnormalities associated with microvascular damage in patients with normal coronary arteries and ischemic-like symptoms. ${ }^{24}$

The progressive myocardial destruction with consequent replacement fibrosis has been described by pathological studies ${ }^{12}$ and can also be observed by CMR. MF was first quantified on LGE-CMR by Rochitte et al., ${ }^{10}$ who demonstrated its presence in 


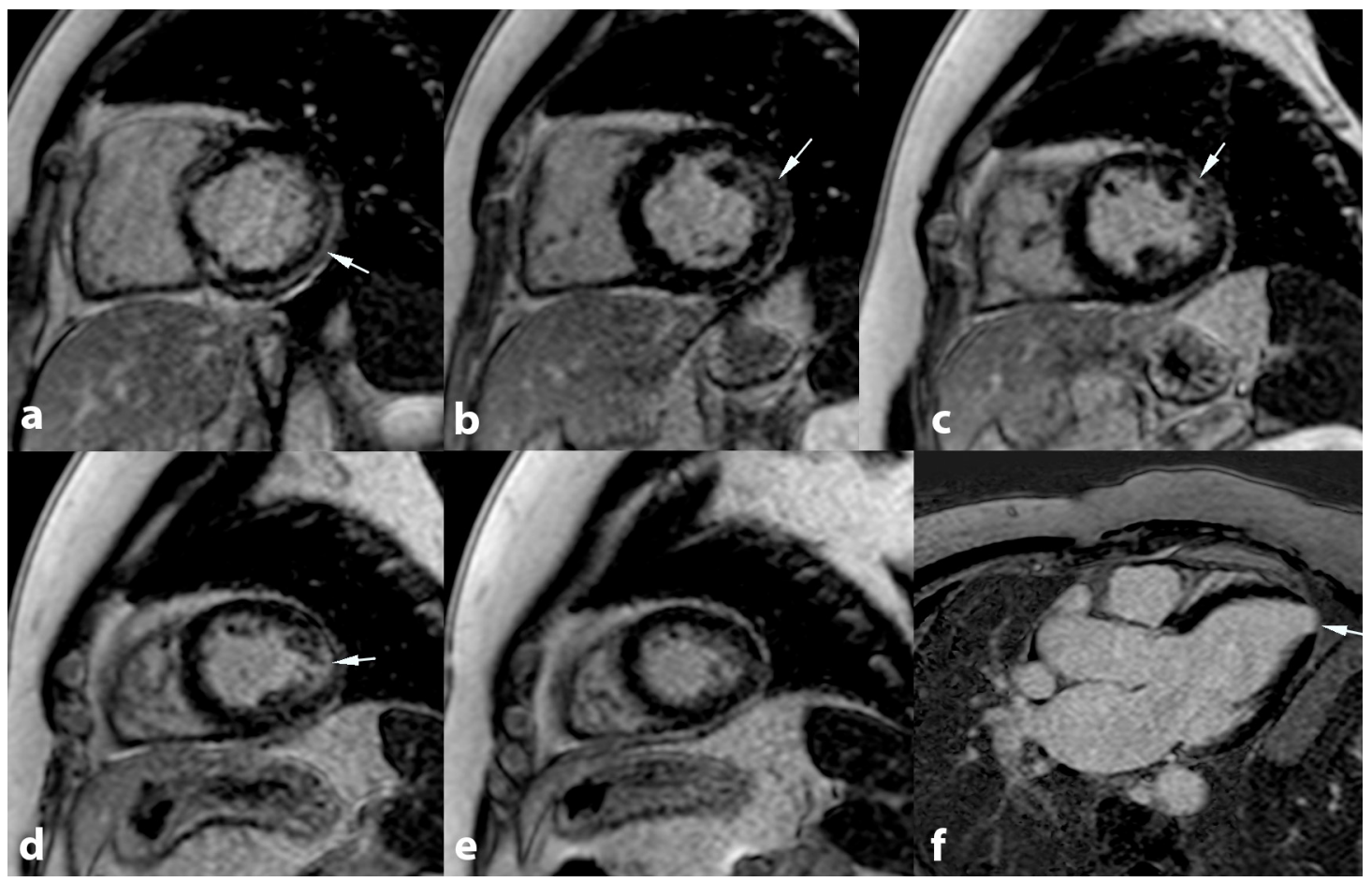

Figure 4 - LGE-CMR showing classic cardiac involvement in chronic Chagas disease ( arrows). In a-e, midwall and subepicardial myocardial fibrosis in the LV inferolateral regions (short axis view). In $\mathrm{f}$, myocardial fibrosis in the LV apex (three-chamber view).

$68.6 \%$ of patients in all cardiac phases of CD. The amount of MF progressively increased from the indeterminate to determinate forms of the disease. The more MF, the worse the ventricular dysfunction and clinical condition of the patient. Researchers also found that the most affected regions were the apex and inferolateral regions of the $\mathrm{LV}$, with a predominance of midwall and subepicardial layers (Figure 4). An atypical pattern was found in $46.9 \%$ of the analyzed LV segments, including subendocardial and transmural patterns that were indistinguishable from the fibrosis secondary to coronary disease (Figure 5). ${ }^{10}$

Another study evaluated sex differences by CMR. Investigators found significantly more fibrosis and ventricular dysfunction in male patients with $C D$ than in female patients. The distribution of MF was also different between both sexes, where men displayed more transmural fibrosis than women. ${ }^{25}$

Finally, considering that an apical ventricular aneurysm increases the risk of intracardiac thrombosis and thromboembolic phenomena, ventricular thrombus can be easily recognized by using LGE-CMR. ${ }^{26}$

\section{CMR as a risk stratification tool}

Sudden cardiac death is responsible for $55 \%$ to $65 \%$ of all deaths in CD. ${ }^{27}$ The close relationship of MF, ventricular arrhythmias, and sudden cardiac death has been described by several studies on ischemic and nonischemic cardiomyopathies. ${ }^{28-32}$

Distinguishing different patterns of MF and determining its extent by LGE-CMR provides important information that allows physicians to distinguish the etiology of cardiomyopathies and improve prognosis scores. White et al..$^{33}$ demonstrated that the etiology of aborted sudden cardiac death or sustained monomorphic ventricular tachycardia was changed in $50 \%$ of the cases where patients were evaluated by CMR in comparison to conventional diagnostic investigation with transthoracic echocardiography and coronary angiography. ${ }^{33}$

The use of MF in the prediction of adverse events in patients with $\mathrm{CD}$ was assessed by Uellendahl et al., ${ }^{34}$ the authors correlated MF with prognostic data using the validated Rassi score, which identifies patients at risk (low, intermediate, or high) of dying prematurely. This correlation 


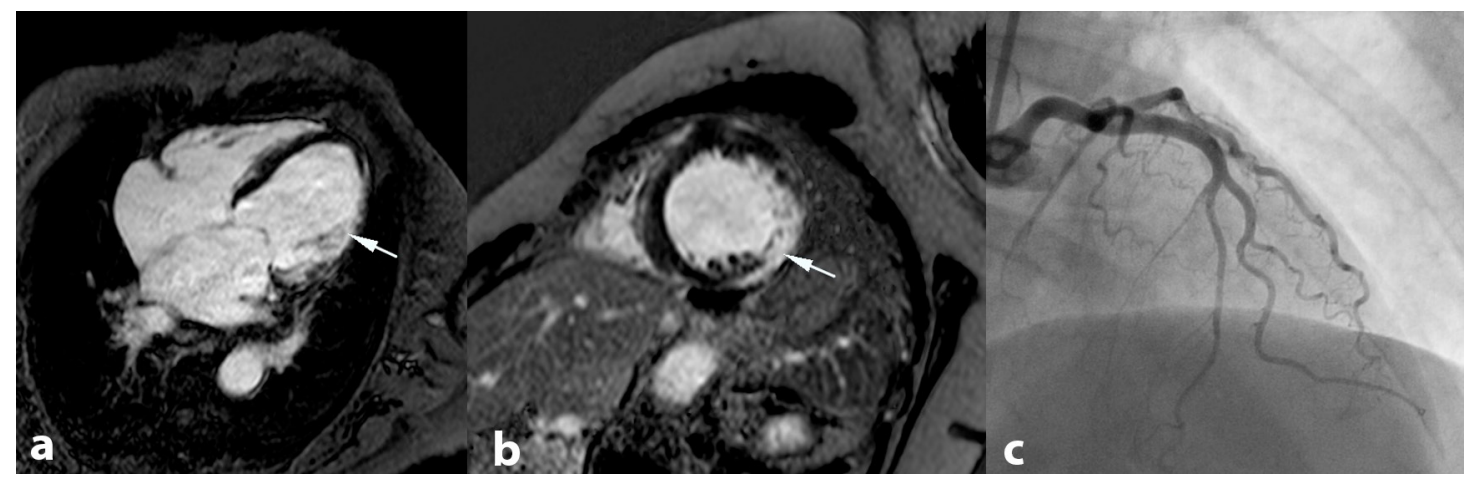

Figure 5 - An 83-year-old woman with positive serological tests for Chagas disease and atypical LGE that simulates transmural infarction. In a and b, myocardial fibrosis in the circumflex artery territory (lateral wall - arrows). In c, coronary angiography showing absence of coronary artery disease.

evidenced a progressive increase in MF from low- to high-risk Rassi score groups and also confirmed a strong association among MF, cardiac dysfunction, and arrhythmia. ${ }^{34}$

Recently, Senra et al., ${ }^{35}$ identified MF in $76.1 \%$ of patients with chronic Chagas cardiomyopathy and defined a cutoff value for the myocardial fibrosis mass of $12.3 \mathrm{~g}$ for predicting the combined endpoint (all-cause mortality, heart transplantation, antitachycardia pacing or appropriate shock from an implantable cardioverter-defibrillator [ICD], and aborted sudden cardiac death). The study had an average follow-up of 5 years with an area under the curve of 0.79 (95\% confidence interval [CI] 0.72-0.87). The MF observed on CMR was an independent predictor of the combined endpoint. ${ }^{35}$

LGE imaging represents a powerful tool to identify patients at higher risk of cardiovascular events and who would benefit from an ICD. ${ }^{36,37}$ Furthermore, the presence of MF in patients with heart failure who underwent device implantation revealed a high likelihood of appropriate ICD therapy, while its absence predicted a low risk of appropriate therapy. ${ }^{38}$

\section{Future perspectives}

T1 mapping and extracellular volume measurements represent potentially powerful emerging techniques that have allowed the assessment of myocardial affection at early stages of CD, where LGE images still cannot be obtained. By employing these techniques, it is possible to assess the replacement and permeation of myocardial tissue in several cardiomyopathy etiologies. ${ }^{39-46}$ Extracellular volume estimation uses hematocrit and $\mathrm{T} 1$ values (pre- and post-contrast) ${ }^{47}$ and has a strong correlation with extracellular matrix. ${ }^{48-50}$ Similarly to LV ejection fraction, the extracellular volume is an important prognostic tool in the evaluation of cardiomyopathies. ${ }^{51,52}$ In CD, native $\mathrm{T} 1$ and extracellular volume increase along with disease severity; abnormal values may be seen even in the indeterminate form of the disease and in regions without MF. This prompts these parameters as tools for identifying and monitoring early myocardial damage, in addition to performing risk stratification (Figure 6). ${ }^{53}$

\section{Conclusions}

Despite the difficulties of using CMR in clinical settings, especially in endemic areas of CD with budget limitations, the early detection of cardiac involvement by CMR has an important impact on the clinical approach and disease prognostics.

Although CD was discovered more than 100 years ago, recent technological advances have allowed a better understanding of this disease and the early detection of cardiac involvement. CMR has the potential to detect not only biventricular systolic dysfunction in the chronic cardiac phase, but also myocardial inflammation (by T2-weighted and early gadolinium enhancement imaging) and MF (by LGE imaging) in the acute and indeterminate phases, even when no other tests show abnormalities.

CMR is also valuable for predicting adverse events. T1 mapping and extracellular volume sequences are promising techniques for assessing Chagas cardiomyopathy before MF becomes apparent. 


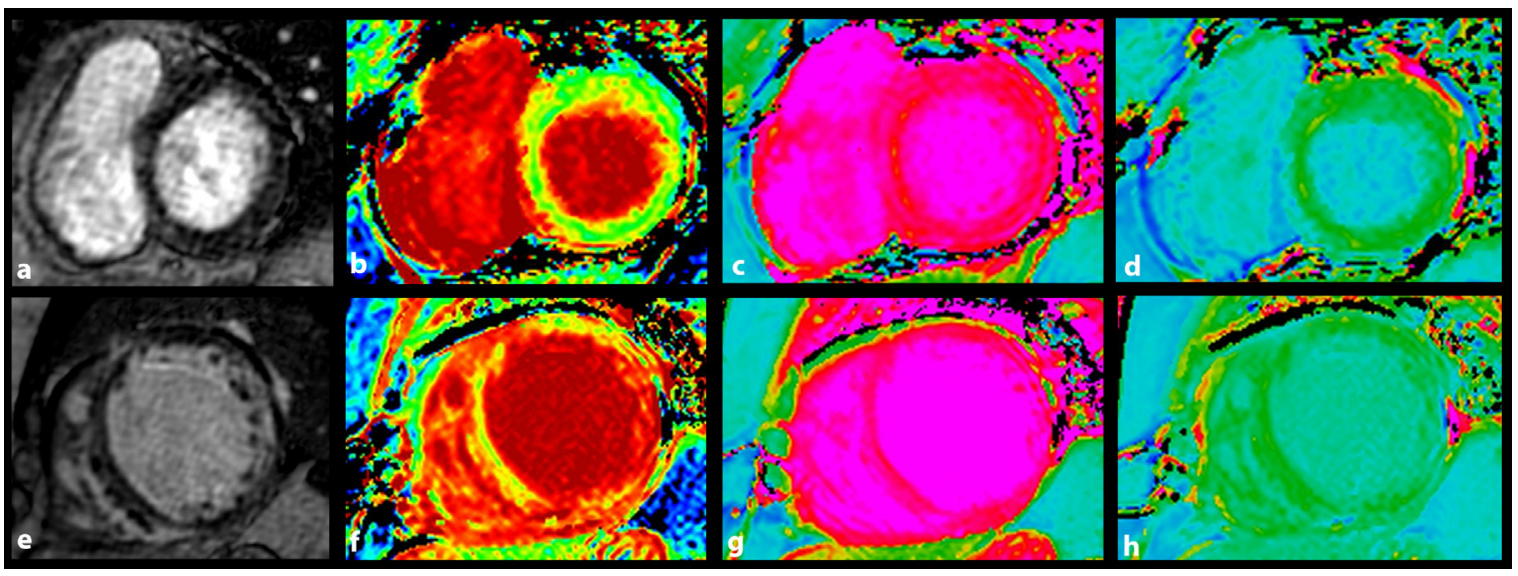

Figure 6 - Examples of LGE, extracellular volume, native and post-contrast T1 mid-cavity short axis images in patients with indeterminate form $(a, b, c$, and $d$, respectively) and with reduced LV ejection fraction ( $e, f, g$, and $h$, respectively). In the indeterminate form, we note homogeneous myocardial signal in all sequences, showing no interstitial enlargement. In the Chronic Chagas cardiomyopathy, we see LGE in inferolateral wall, interventricular septum and myocardial junctions; in T1 mapping and extracellular volume sequences, those alterations are more pronounced, showing interstitial fibrosis in LGE-negative areas, as anterolateral and inferior walls.

\section{Author contributions}

Conception and design of the research: Pacheco AB. Rochitte CE. Acquisition of data: Pacheco AB, Melo, RJL. Analysis and interpretation of the data: Pacheco $\mathrm{AB}$, Rochitte, $\mathrm{CE}$. Writing of the manuscript: Pacheco $\mathrm{AB}$, Melo, RJL. Critical revision of the manuscript for intellectual content: Rochitte CE.

\section{Potential Conflict of Interest}

No potential conflict of interest relevant to this article was reported.

\section{References}

1. Conteh L, Engels T, Molyneux DH. Socioeconomic aspects of neglected tropical diseases. Lancet. 2010;375:239-247. doi:10.1016/S01406736(09)61422-7.

2. Basile L, Jansà JM, Carlier Y, Salamanca DD, Angheben A, Bartoloni A, et al. Chagas disease in European countries : the challenge of a surveillance system. Eurosurveillance.2011 Sep;16(37):1-10;

3. Acosta IC, Pérez-Tanoira R, Prieto-Pérez L, Úbeda AC, Álvarez Álvarez B, Antoranz PA, et al. Chagas' heart disease: Descriptive analysis of 141 patients in a hospital of Madrid, Spain. Travel Med Infect Dis. 2020. doi:10.1016/j.tmaid.2020.101690.

4. Antinori S, Galimberti L, Bianco R, Grande R, Galli M, Corbellino M. European Journal of Internal Medicine Chagas disease in Europe : A review for the internist in the globalized world. Eur J Intern Med. 2017.43:6-15 doi:10.1016/j.ejim.2017.05.001.

5. Nunes MCP, Badano LP, Marin-Neto JA, Edvardsen T, FernándezGolfín C, Bucciarelli-Ducci C, et al. Multimodality imaging evaluation of

\section{Sources of Funding}

There were no external funding sources for this study.

\section{Study Association}

This study is not associated with any thesis or dissertation work.

\section{Ethics approval and consent to participate}

This article does not contain any studies with human participants or animals performed by any of the authors.

Chagas disease: an expert consensus of Brazilian Cardiovascular Imaging Department (DIC) and the European Association of Cardiovascular Imaging (EACVI). Eur Heart J Cardiovasc Imaging. 2018;19(4):459-60n. doi:10.1093/ehjci/jex154.

6. Sales Jr PA, Molina I, Murta SM, Sanchez-Montalva A, Salvador F, Correa-Oliveira R, et al. Experimental and Clinical Treatment of Chagas Disease [review] Am J Trop Med Hyg. 2017;97(5):1289-303.

7. Rassi A, Rassi A, Marin-Neto JA. Chagas disease. Lancet. 2010;375(9723):1388-402. doi:10.1016/S0140-6736(10)60061-X.

8. Rochitte CE, Nacif MS, De Oliveira Júnior AC, Siqueira-Batista R, Marchiori E, Uellendahl M, et al. Cardiac magnetic resonance in Chagas' disease. Artif Organs. 2007;31(4):259-67. doi:10.1111/j.1525-1594.2007.00373.x.

9. Diaz A, Diaztagle JJ, Olaya A, Mora G, López-Lima I, Ayala C, et al. Cardiovascular Magnetic Resonance Imaging Evidence of Edema in Chronic Chagasic Cardiomyopathy. Cardiol Res Pract. 2019;2019. doi:10.1155/2019/6420364. 
10. Rochitte CE, Oliveira PF, Andrade JM, Ianni BM, Parga JR, Ávila LF, et al. Myocardial delayed enhancement by magnetic resonance imaging in patients with Chagas' disease: A marker of disease severity. J Am Coll Cardiol. 2005;46(8):1553-8. doi:10.1016/j.jacc.2005.06.067.

11. Torreão JA, Ianni BM, Mady C, Naia E, Rassi CH, Nomura C, et al. Myocardial tissue characterization in Chagas' heart disease by cardiovascular magnetic resonance. J Cardiovasc Magn Reson. 2015;17:1-11. doi:10.1186/s12968-015-0200-7.

12. Barretto ACP, Mady C, Arteage-Fernandez E, Stolf N, Lopes EA, de Lourdes Higuchi M, et al. Right ventricular endomyocardial biopsy in chronic Chagas' disease. Am Heart J. 1986;111(2):307-12. doi:10.1016/00028703(86)90144-4.

13. Maya JD, Orellana M, Ferreira J, Kemmerling U, López-Muñoz R, Morello A. Chagas disease: Present status of pathogenic mechanisms and chemotherapy. Biol Res. 2010;43(3):323-31. doi:10.4067/S071697602010000300009

14. Marin-Neto JA, Simões MV, Sarabanda ÁVL. Chagas' heart disease. Arq Bras Cardiol. 1999;72(3):247-80. doi:10.1590/S0066-782X1999000300001.

15. Moreira HT, Volpe GJ, Trad HS, Santos MK, Romano MD, Pazin-Filho AT, et al. Right ventricular dysfunction in Chagas' Cardiomyopathy. Primary involvement or a resonant manifestation of Left ventricular dysfunction? J Cardiovasc Magn Reson. 2014;16(Suppl 1):P301. doi:10.1186/1532-429x-16s1-p301.

16. Moreira HT, Volpe GJ, Marin-Neto JA, Ambale-Venkatesh B, Nwabuo CC, Trad HS, et al. Evaluation of Right Ventricular Systolic Function in Chagas Disease Using Cardiac Magnetic Resonance Imaging. Circ Cardiovasc Imaging. 2017;10 (3):e005571. doi:10.1161/CIRCIMAGING.116.005571.

17. Amzulescu MS, De Craene M, Langet H, Pasquet A, Vancraeynest D, Pouleur AC, et al. Myocardial strain imaging: review of general principles, validation, and sources of discrepancies. Eur Heart J Cardiovasc Imaging. 2019;20(6):605-619. doi:10.1093/ehjci/jez041.

18. Fernandes F, Moreira CHV, Barbosa-Ferreira JM, Sabino EC. Imaging Diagnosis of Right Ventricle Involvement in Chagas Cardiomyopathy. Biomed Res Int.2017; ID 3820191:14

19. Moreira HT, Volpe GJ, Marin-Neto JA, Nwabuo CC, Ambale-Venkatesh B, Gali LG, et al. Right Ventricular Systolic Dysfunction in Chagas Disease Defined by Speckle-Tracking Echocardiography: A Comparative Study with Cardiac Magnetic Resonance Imaging. J Am Soc Echocardiogr. 2017;30(5):493-502. doi:10.1016/j.echo.2017.01.010.

20. Barbosa MM, Rocha MOC, Vidigal DF, De Carvalho Bicalho Carneiro R, Araújo RD, Palma MC, et al. Early detection of left ventricular contractility abnormalities by two-dimensional speckle tracking strain in Chagas' disease. Echocardiography. 2014;31(5):623-30. doi:10.1111/echo.12426.

21. Santos OR, da Costa Rocha MO, de Almeida FR, da Cunha PFS, Souza SCS, Saad GP, et al. Speckle tracking echocardiographic deformation indices in Chagas and idiopathic dilated cardiomyopathy: Incremental prognostic value of longitudinal strain. PLoS One. 2019;14:1-14. doi:10.1371/journal. pone.0221028.

22. Pryds K, Larsen AH, Hansen MS, Grøndal AYK, Tougaard RS, Hansson $\mathrm{NH}$, et al. Myocardial strain assessed by feature tracking cardiac magnetic resonance in patients with a variety of cardiovascular diseases - A comparison with echocardiography. Sci Rep. 2019;9(1):11296. doi:10.1038/ s41598-019-47775-4.

23. Gomes VAM, Alves GF, Hadlich M, Azevedo CF, Pereira IM, Santos CRF, et al. Analysis of Regional Left Ventricular Strain in Patients with Chagas Disease and Normal Left Ventricular Systolic Function. J Am Soc Echocardiogr. 2016 Jul;29(7):679-88.

24. Marin-neto JA, Simões MV, Junior AR. Pathogenesis of chronic Chagas cardiomyopathy : the role of coronary microvascular derangements Rev Soc Bras Med Trop.2013;46(5):536-41.

25. Assunção AN, Jerosch-Herold M, Melo RL, Mauricio A V., Rocha L, Torreão JA, et al. Chagas' heart disease: gender differences in myocardial damage assessed by cardiovascular magnetic resonance. J Cardiovasc Magn Reson. 2016;18(1):88. doi:10.1186/s12968-016-0307-5.
26. Velangi PS, Choo C, Chen KHA, Kazmirczak F, Nijjar PS, FarzanehFar A, et al. Long-Term Embolic Outcomes After Detection of Left Ventricular Thrombus by Late Gadolinium Enhancement Cardiovascular Magnetic Resonance Imaging: A Matched Cohort Study. Circ Cardiovasc Imaging. 2019;12(11):e009723. doi:10.1161/ CIRCIMAGING.119.009723.

27. Rassi A, Rassi SG, Rassi A. Sudden death in chagas' disease. Arq Bras Cardiol. 2001;76(1):75-96. doi:10.1590/s0066-782×2001000100008.

28. Kim RJ, Fieno DS, Parrish TB, Harris K, Chen E-L, Simonetti O, et al. Relationship of MRI Delayed Contrast Enhancement to Irreversible Injury, Infarct Age, and Contractile Function. Circulation. 1999;100(19):1992-2002. doi:10.1161/01.CIR.100.19.1992.

29. Moll-Bernardes RJ, Rosado-De-Castro PH, Camargo GC, Sardinha Mendes FSN, Brito ASX, Sousa AS. New imaging parameters to predict sudden cardiac death in Chagas disease. Trop Med Infect Dis. 2020;5(2):74. doi:10.3390/tropicalmed5020074.

30. Volpe GJ, Moreira HT, Trad HS, Wu KC, Braggion-Santos MF, Santos MK, et al. Left Ventricular Scar and Prognosis in Chronic Chagas Cardiomyopathy. J Am Coll Cardiol. 2018;72(1):2567-76. doi:10.1016/j. jacc.2018.09.035.

31. Chan RH, Maron BJ, Olivotto I, Pencina MJ, Assenza GE, Haas T, et al. Prognostic value of quantitative contrast-enhanced cardiovascular magnetic resonance for the evaluation of sudden death risk in patients with hypertrophic cardiomyopathy. Circulation. 2014;130(6):484-95. doi:10.1161/CIRCULATIONAHA.113.007094.

32. Mahida S, Sacher F, Dubois R, Sermesant M, Bogun F, Haïssaguerre M, et al. Cardiac Imaging in Patients With Ventricular Tachycardia. Circulation. 2017;136(25):2491-507. doi:10.1161/CIRCULATIONAHA.117.029349.

33. White JA, Fine NM, Gula L, Yee R, Skanes A, Klein G, et al. Utility of cardiovascular magnetic resonance in identifying substrate for malignant ventricular arrhythmias. Circ Cardiovasc Imaging. 2012;5(1):12-20. doi:10.1161/CIRCIMAGING.111.966085.

34. Uellendahl M, Siqueira MEM de, Calado EB, Kalil-Filho R, Sobral D Ribeiro C, et al. Cardiac Magnetic Resonance-Verified Myocardial Fibrosis in Chagas Disease: Clinical Correlates and Risk Stratification. Arq Bras Cardiol. 2016;107(5):460-6. doi:10.5935/abc.20160168.

35. Senra T, Ianni BM, Costa ACP, Mady C, Martinelli-Filho M, Kalil-Filho $\mathrm{R}$, et al. Long-Term Prognostic Value of Myocardial Fibrosis in Patients With Chagas Cardiomyopathy. J Am Coll Cardiol. 2018;72(21):2577-87. doi:10.1016/j.jacc.2018.08.2195.

36. Elming MB, Hammer-Hansen S, Voges I, Nyktari E, Raja AA, Svendsen $\mathrm{JH}$, et al. Myocardial fibrosis and the effect of primary prophylactic defibrillator implantation in patients with non-ischemic systolic heart failure-DANISH-MRI. Am Heart J. 2020 Mar;221:165-76.doi:10.1016/ jjjjahj.2019.10.020.

37. Jablonowski R, Chaudhry U, Van Der Pals J, Engblom H, Arheden $\mathrm{H}$, Heiberg E, et al. Cardiovascular magnetic resonance to predict appropriate implantable cardioverter defibrillator therapy in ischemic and nonischemic cardiomyopathy patients using late gadolinium enhancement border zone comparison of four analysis methods. Circ Cardiovasc Imaging. 2017; 10(9):e006105. doi:10.1161/ CIRCIMAGING.116.006105.

38. Iles L, Pfluger H, Lefkovits L, Butler MJ, Kistler PM, Kaye DM, et al Myocardial fibrosis predicts appropriate device therapy in patients with implantable cardioverter-defibrillators for primary prevention of sudden cardiac death. J Am Coll Cardiol. 2011;57(7):821-8. doi:10.1016/j. jacc.2010.06.062.

39. Messroghli DR, Niendorf T, Schulz-Menger J, Dietz R, Friedrich MG T1 Mapping in Patients with Acute Myocardial Infarction. J Cardiovasc Magn Reson. 2003;5(2):353-9. doi:10.1081/JCMR-120019418.

40. Ugander M, Bagi PS, Oki AJ, Chen B, Hsu Y, Aletras AH, et al Myocardial edema as detected by pre-contrast T1 and T2 MRI delineates area at risk associated with acute myocardial infarction. JACC Cardiovasc Imaging. 2012;5(6):596-603. doi:10.1016/j.jcmg.2012.01.016. 
41. Ferreira VM, Piechnik SK, Dall'Armellina E, Karamitsos TD, Francis JM, Choudhury RP, et al. Non-contrast T1-mapping detects acute myocardial edema with high diagnostic accuracy: a comparison to T2-weighted cardiovascular magnetic resonance. J Cardiovasc Magn Reson. 2012;14(1):42. doi:10.1186/1532-429X-14-42.

42. Karamitsos TD, Piechnik SK, Banypersad SM, Fontana M, Ntusi NB, Ferreira VM, et al. Noncontrast T1 mapping for the diagnosis of cardiac amyloidosis. JACC Cardiovasc Imaging. 2013;6(4):488-97. doi:10.1016/j. jcmg.2012.11.013.

43. Bull S, White SK, Piechnik SK, Flett AS, Ferreira VM, Loudon M, et al. Human non-contrast T1 values and correlation with histology in diffuse fibrosis. Heart. 2013;99(13):932-7. doi:10.1136/heartjnl-2012-303052.

44. Sado DM, White SK, Piechnik SK, Banypersad SM, Treibel T, Captur G, et al. Identification and assessment of Anderson-Fabry disease by cardiovascular magnetic resonance noncontrast myocardial T1 mapping. Circ Cardiovasc Imaging. 2013;6(3):392-8. doi:10.1161/CIRCIMAGING.112.000070.

45. Scholz TD, Fleagle SR, Parrish FC, Breon T, Skorton DJ. Effect of tissue fat and water content on nuclear magnetic resonance relaxation times of cardiac and skeletal muscle. Magn Reson Imaging. 1990;8(5):605-11. doi:10.1016/0730-725x(90)90138-r.

46. Pedersen SF, Thrysøe S a, Robich MP, Paaske WP, Ringgaard S, Bøtker $\mathrm{HE}$, et al. Assessment of intramyocardial hemorrhage by T1-weighted cardiovascular magnetic resonance in reperfused acute myocardial infarction. J Cardiovasc Magn Reson. 2012;14(1):59. doi:10.1186/1532429X-14-59.

47. Kellman P, Wilson JR, Xue H, Ugander M, Arai AE. Extracellular volume fraction mapping in the myocardium, part 1: evaluation of an automated method. J Cardiovasc Magn Reson. 2012;14(1):63. doi:10.1186/1532-429X-14-63.
48. Fontana M, White SK, Banypersad SM, Sado DM, Maestrini V, Flett AS, et al. Comparison of T1 mapping techniques for ECV quantification. Histological validation and reproducibility of ShMOLLI versus multibreath-hold T1 quantification equilibrium contrast CMR. J Cardiovasc Magn Reson. 2012;14(1):88. doi:10.1186/1532-429X-14-88.

49. Flett AS, Hayward MP, Ashworth MT, Hansen MS, Taylor AM, Elliott $\mathrm{PM}$, et al. Equilibrium contrast cardiovascular magnetic resonance for the measurement of diffuse myocardial fibrosis: preliminary validation in humans. Circulation. 2010;122(2):138-44. doi:10.1161/ CIRCULATIONAHA.109.930636.

50. Miller CA, Naish JH, Bishop P, Coutts G, Clark D, Zhao S, et al. Comprehensive validation of cardiovascular magnetic resonance techniques for the assessment of myocardial extracellular volume. Circ Cardiovasc Imaging. 2013;6(3):373-83. doi:10.1161/ CIRCIMAGING.112.000192.

51. Wong TC, Piehler K, Meier CG, Testa SM, Klock AM, Aneizi AA, et al. Association between extracellular matrix expansion quantified by cardiovascular magnetic resonance and short-term mortality. Circulation. 2012;126(10):1206-16. doi:10.1161/CIRCULATIONAHA.111.089409.

52. Wong TC, Piehler KM, Kang IA, Kadakkal A, Kellman P, Schwartzman DS, et al. Myocardial extracellular volume fraction quantified by cardiovascular magnetic resonance is increased in diabetes and associated with mortality and incident heart failure admission. Eur HeartJ. 2014;35(10):657-64. doi:10.1093/eurheartj/eht193.

53. Melo R de JL. Interstitial myocardial fibrosis in Chagas cardiomyopathy - assessment of T1 mapping and myocardial extracellular volume by cardiovascular magnetic resonance. [thesis]. São Paulo: Faculdade de Medicina/ USP ; 2019. 